\title{
SISTEMAS AMBIENTAIS E DESMATAMENTO NA REGIÃO DA BACIA HIDROGRÁFICA DO RIO APODI-MOSSORÓ/RN
}

\section{Environmental Systems and Deforestation in the River Apodi-Mossoró Watershed Zone, State of Rio Grande do Norte}

\author{
Rodrigo Guimarães Carvalho ${ }^{1}$
}

\author{
$a a a_{a a}$
}

\begin{abstract}
Resumo
O desmatamento excessivo é um dos principais problemas ambientais nas bacias hidrográficas brasileiras. Problemas como erosão, assoreamento e a perda de biodiversidade estão fortemente associados ao acentuado desmatamento em todos os biomas do Brasil. A presente pesquisa buscou discutir o cenário de desmatamento e a sustentabilidade dos sistemas ambientais na região da bacia hidrográfica do rio Apodi-Mossoró (BHRAM), estado do Rio Grande do Norte (RN). Para isso, foram compartimentados os sistemas ambientais em escala de 1: 250.000 e acoplados a essa base os dados sobre o desmatamento da área em questão. A região da BHRAM apresenta $37,8 \%$ de áreas desmatadas, contudo, a planície fluvial e a planície flúvio-marinha são os sistemas ambientais com maior percentual de desmatamento, respectivamente, $74 \%$ e $58 \%$. As maiores áreas desmatadas estão na chapada do Apodi com $1.670 \mathrm{~km} 2$ e na depressão sertaneja com $1.679 \mathrm{~km} 2$.
\end{abstract}

Palavras-chave: Manejo de Bacias Hidrográficas, Monitoramento do Bioma Caatinga, Cartografia Digital.

\begin{abstract}
The excessive deforestation is one of the main environmental problems in the Brazilian watersheds. Issues such as erosion, silting and biodiversity loss are strongly associated tosevere deforestation in all Brazilian biomes. This study aimed at discussing the scenario of deforestation and the sustainability of the environmental systems in the zone ofthe Bacia Hidrográfica do Rio Apodi-Mossoró (BHRAM), state of Rio Grande do Norte (RN). For this, environmental systems were partitioned on a 1:250,000 scale and the data on the deforestation of the subject area were engaged to this base. The BHRAM zone presents $37.8 \%$ of deforested areas; however, the fluvial plain and fluvial-marine plain are the environmental systems with the highest percentage of deforestation, respectively, $74 \%$ and $58 \%$. The largest deforested zones are in the plateau of Apodi with 1,670 sqm and in the backcountry depression with 1,679 sqm.
\end{abstract}

Key words: Watershed Management, Monitoring of the Caatinga Biome, Digital Cartography.

\begin{abstract}
Résumé
Le déboisement excessif est un des problèmes d'environnement majeurs dans les bassins versants brésiliens. Des problèmes tels que l'érosion, la sédimentation et la perte de la biodiversité sont fortement associées à la déforestation nette dans tous les biomes du Brésil. La présente recherche visait à discuter du scénario de déforestation et de la durabilité environnementale de la région du bassin hydrographique du fleuve Apodi-Mossoró (BHRAM), de l'état du Rio Grande do Norte (RN). Pour cela, les systèmes environnementaux ont été compartimentés à l'échelle de 1: 250.000 et couplésà cette baseles données de déforestation de la région en question. La région de BHRAM présente $37,8 \%$ de zones déboisées, cependant, la plaine fluviale et la plaine fluvio-marine sont des systèmes environnementaux avec un pourcentage plus élevé de déforestation, respectivement, $74 \%$ et $58 \%$. Les plus grandes zones déboisés sont dans lePlateau d'Apodi avec $1670 \mathrm{~km} 2$ et dans la dépression sertaneja avec $1679 \mathrm{~km} 2$.
\end{abstract}

Mots-clés: Gestion des bassins versants, Surveillance du biome Caatinga, Cartographie numérique.

(1) Prof. Dr. do Departamento de Gestão Ambiental da Universidade do Estado do Rio Grande do Norte - Rua Almino Afonso, 478, CEP: 59610-2 10, Mossoro (RN), Brasil. Tel.: (+55 85) 38932181 - rodrigo.ufc@gmail.com

\section{aaAaa}

Revista da ANPEGE, v. 8, n. 9, p. 107-118, jan./jul. 2012.

ISSN 1679-768 X @ @ 2003, Associação Nacional de Pesquisa e Pós-Graduação em Geografia. Todos os direitos reservados. 


\section{INTRODUÇÃO}

O Ministério do Meio Ambiente do Brasil (MMA) divulgou no primeiro semestre de 2010, dados atualizados sobre o monitoramento do desmatamento no Bioma Caatinga. O projeto "Monitoramento do Desmatamento nos Biomas Brasileiros por Satélite" vem sendo desenvolvido sob a coordenação do MMA e está inserido no "Projeto de Conservação e Utilização Sustentável da Diversidade" (PROBIO). O monitoramento do Bioma Caatinga até o ano de 2002 teve, em 2007, seus resultados publicados e utilizou escala final de 1: 250.000. Posteriormente, uma nova etapa foi desenvolvida e resultou na publicação, em 2010, dos resultados cumulativos do monitoramento anteriormente citado, sua adaptação para a escala de 1: 50.000, com a inserção de novas áreas não detectadas em função da qualidade das imagens e escala adotada, bem como, a atualização das áreas desmatadas entre os anos de 2002 e 2008 (MMA, 2010).

$\mathrm{Na}$ abrangência do Bioma Caatinga existem inúmeras bacias hidrográficas vinculadas a uma situação climática preponderantemente semiárida e submetidas a processos de uso e ocupação que, historicamente, tem conduzido a processos de degradação ambiental. Entre esses processos destaca-se o desmatamento para atividades agrícolas, pecuárias, comercialização da lenha e para a expansão de cidades.

Para Cunha e Guerra (2000) o desmatamento deve ser levado em consideração na intensificação dos processos de degradação ambiental, contudo, os autores apontam que se for seguido de um manejo adequado do solo, a degradação pode não acontecer. Já para Sánchez (2006) a degradação refere-se a qualquer estado de alteração de um ambiente, de modo que, nessa linha de pensamento, qualquer desmatamento é uma forma de degradação e o que irá variar é a intensidade e o comprometimento da qualidade ambiental. $\mathrm{O}$ fato é que o desmatamento representa uma alteração na estrutura natural de um sistema ecológico/ambiental e pode ter uma repercussão negativa para a sustentabilidade de uma bacia hidrográfica na medida em que ocorra sem o devido controle ambiental e incida sobre "ambientes fortemente instáveis" (TRICART, 1977).

Mediante a conjuntura socioeconômica atual, o desmatamento é uma prática inevitável, cabendo aos órgãos de planejamento e gestão ambiental controlá-lo de modo a manter a qualidade ambiental e a sustentabilidade dos recursos naturais. Existem legislações específicas que tratam da proteção de parcelas de mata de importância fundamental para a manutenção dos processos ecológicos, estabilização dos solos e conservação da qualidade dos recursos hídricos. A principal delas, o Código Florestal (Lei 4771/1965), passa atualmente por profundas revisões no âmbito do poder legislativo brasileiro. O principal legado deixado pelo Código Florestal ainda vigente é a necessidade de manutenção das Áreas de Preservação Permanente (APPs) e das Reservas Legais, que no Bioma Caatinga se referem a $20 \%$ da área total de um empreendimento.

Para controlar o desmatamento, faz-se necessário, inicialmente, a geração de informações concisas que subsidiem ações administrativas, e, em sentido mais amplo, o planejamento e a gestão ambiental de bacias hidrográficas, e os dados publicados no âmbito do projeto "Monitoramento do Desmatamento nos Biomas Brasileiros por Satélite" são de grande importância para esse fim.

A bacia hidrográfica do rio Apodi-Mossoró (BHRAM) é a segunda maior bacia hidrográfica do estado do Rio Grande do Norte, apresentando uma grande importância econômica impulsionada pelas atividades de extração do petróleo, produção de sal marinho, utilização dos solos para agricultura e fruticultura irrigada, pecuária extensiva e mineração de calcário. Todas essas atividades têm contribuído para ampliar o desmatamento na BHRAM gerando desequilíbrios e comprometendo a qualidade ambiental.

Diante do exposto, o presente trabalho busca discutir o cenário de desmatamento e a sustentabilidade dos sistemas ambientais da região da BHRAM. Têm como objetivos específicos, compartimentar e analisar os sistemas ambientais físicos da região da BHRAM, verificar a distribuição do desmatamento por sistemas ambientais da BHRAM e, por meio do diagnóstico atual, propor medidas de gestão visando a sustentabilidade das unidades de paisagem. 


\section{MATERIAIS E MÉTODOS}

A área da BHRAM está localizada na Região Oeste do estado do Rio Grande do Norte (Figura 1). Engloba territórios de 51 municípios e é o objeto material da presente investigação científica.

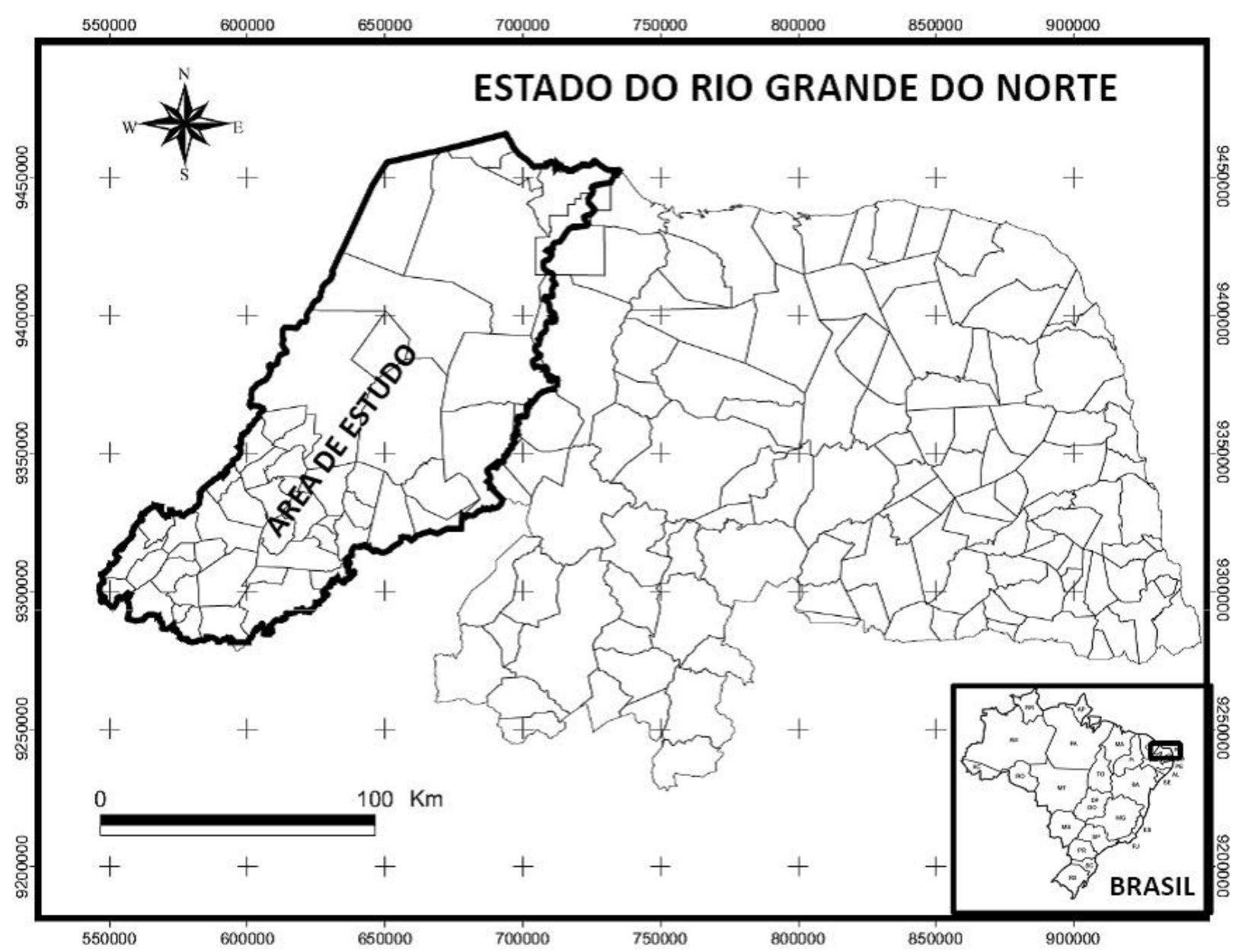

Figura 1 - Localização geográfica da região da BHRAM.

Fonte: Carvalho (2011)

A primeira etapa do trabalho consistiu em compartimentar e analisar os sistemas ambientais da BHRAM. A compartimentação baseou-se no paradigma sistêmico dando ênfase à percepção de conjunto e às interações entre os diversos componentes ambientais, não devendo ser considerada como um fim em si, mas somente como um meio de aproximação em relação com a realidade geográfica (BERTRAND, 1969).

O suporte metodológico está balizado na concepção geossistêmica da análise ambiental onde busca-se a vinculação em um mesmo nível de importância, de todos os componentes ambientais na evolução do sistema, sendo inclusive possível, a inserção da variável antrópica uma vez que essa demonstre competência e significância nas interações com o ambiente. Como expressa Christofoletti (1999, p. 44), sobre a análise dos sistemas ambientais físicos, "não se pode excluir o conhecimento provindo dos estudos sobre os sistemas socioeconômicos". Porém, é preciso compreender a ação antrópica como uma intervenção externa ao sistema ambiental físico, pois como mencionam Bertrand Bertrand e Passos (2007), a existência de um componente antrópico não significa que este seja subordinado ao geossistema, pois as relações internas nos geossistemas são submetidas às leis naturais, enquanto que a ação antrópica está submetida às leis socioeconômicas. Sendo assim a ação antrópica se posiciona como uma relação externa e dialética ao geossistema. 
Na região da BHRAM, o critério mais indicado para a delimitação dos sistemas ambientais é a compartimentação das unidades geomorfológicos (CARVALHO, 2011). Autores como Sousa (2007), Soares (2001) e Rodriguez, Silva e Cavalcanti (2004) concordam que a geomorfologia é um atributo fundamental para sintetizar as condições ambientais e possibilitar uma delimitação mais precisa dos arranjos espaciais com padrões de funcionamento próprios, capaz de individualizá-los quanto aos fluxos de energia e matéria e o nível de equilíbrio dinâmico. Os dados sobre o desmatamento na BHRAM foram inseridos com a finalidade de entender o quadro atual de exploração antrópica sobre os sistemas ambientais físicos.

Utilizou-se para o mapeamento materiais geocartográficos digitais referentes aos temas: geologia, geomorfologia, recursos hídricos e solos. Por meio da análise conjunta desse material, junto à imagem LANDSAT 7 ETM+ de 2005 e de etapas de campo foi possível delimitar os sistemas ambientais em escala de mapeamento de 1: 250.000.

$\mathrm{O}$ enquadramento desses sistemas ambientais na proposta metodológica da ecodinâmica de Tricart (1977) ocorreu a partir da análise qualitativa da dinâmica ambiental, considerando elementos como a estrutura das rochas, as declividades, o padrão de drenagem, os tipos de solos e a estrutura do revestimento vegetal. Desse modo, os sistemas ambientais foram classificados em estáveis, de transição ou fortemente instáveis, mediante a situação do balanço morfogênese/pedogênese.

Os dados sobre o desmatamento da BHRAM foram inseridos em software específico de geoprocessamento e receberam tratamento utlizando-se técnicas de cartografia digital, especialmente, $o$ recorte e o cálculo de áreas. Depois foram calculadas as áreas totais de desmatamento nos sistemas ambientais e elaboradas as propostas de gestão.

\section{RESULTADOS E DISCUSSÕES}

\section{COMPARTIMENTAÇÃO E ANÁLISE DOS SISTEMAS AMBIENTAIS DA REGIÃO DA BHRAM}

Os domínios de paisagem que subscrevem os sistemas ambientais físicos na região da BHRAM estão dispostos na Figura 2. Cabe ressaltar o caráter genérico dessa delimitação em função da escala de mapeamento adotada (1: 250.000). As feições geomorfológicas de menor dimensão territorial foram incorporadas aos sistemas geomorfológicos ao qual estavam inscritas. Foi o caso dos platôs que foram acoplados aos maciços residuais e dos inselbergs e pães de açúcar que foram incorporados a depressão sertaneja. Essas mudanças têm como objetivo ajustar os sistemas ambientais à escala pretendida de análise.

Os sistemas ambientais da BHRAM têm na chapada do Apodi e na depressão sertaneja as maiores áreas territoriais. Juntas, essas unidades representam $68 \%$ da área total. A depressão periférica ( $9 \%$ ), os maciços residuais $(9 \%)$ e o tabuleiro costeiro $(9,6 \%)$ representam juntos $27,6 \%$ da área. Já a planície litorânea, a planície fluvial e a planície flúvio-marinha, respectivamente, com $0,4 \%, 2,3 \%$ e 1,7\%, são as unidades de menor dimensão territorial (Figura 3).

Apesar da grande quantidade de cursos d'água superficiais, a planície fluvial considerada como sistema ambiental se refere aos setores marginais do rio Apodi-Mossoró e do rio do Carmo quando estes adentram a chapada do Apodi e assumem uma maior dimensão territorial. Destaca-se que a escala de análise cartográfica não permitiu considerar as áreas de planície fluvial restantes, por possuírem uma dimensão territorial incompatível com sua representação no mapeamento. 


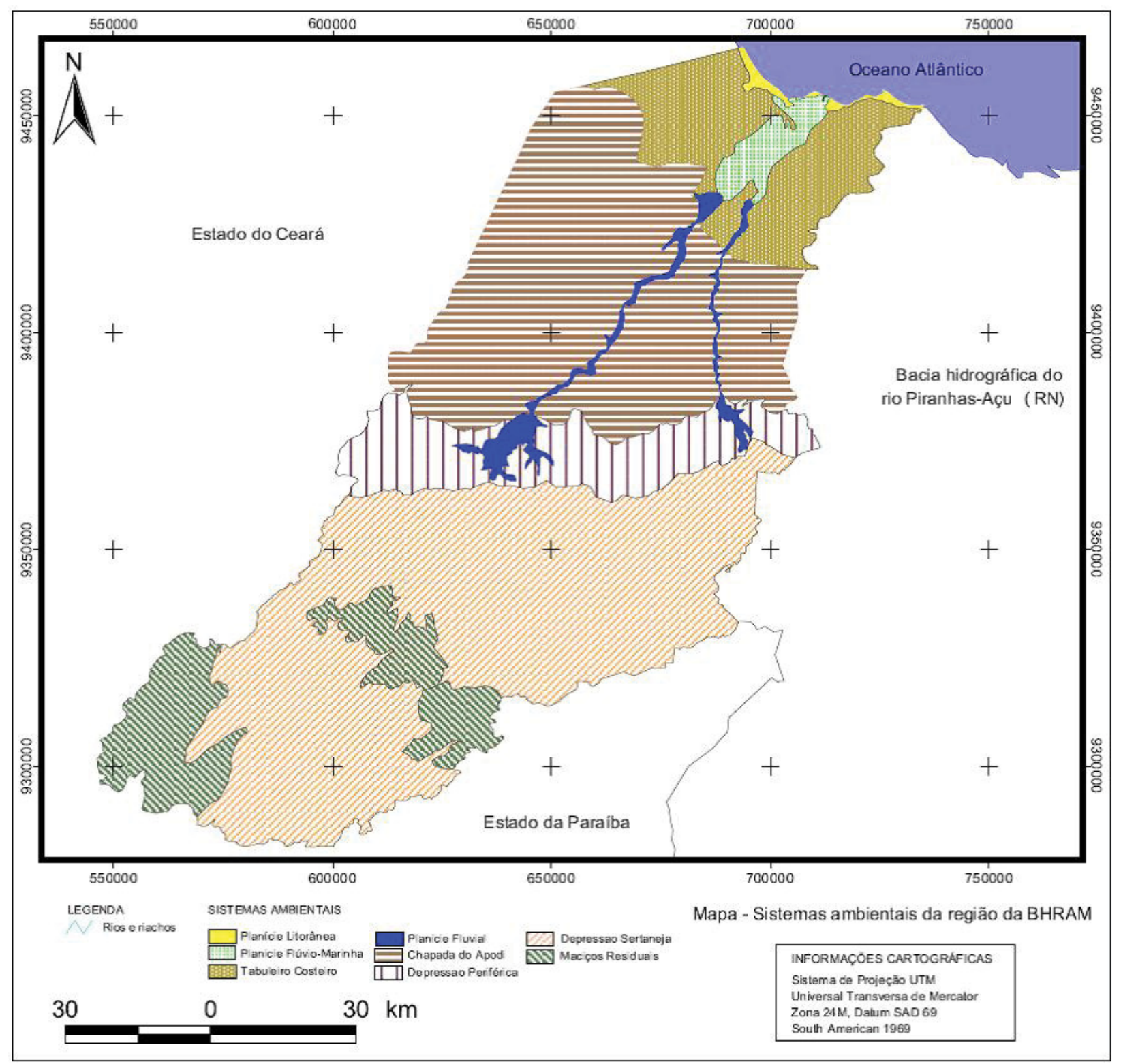

Figura 2 - Compartimentação dos sistemas ambientais da região da BHRAM. Fonte: Adaptado de Carvalho (2011).

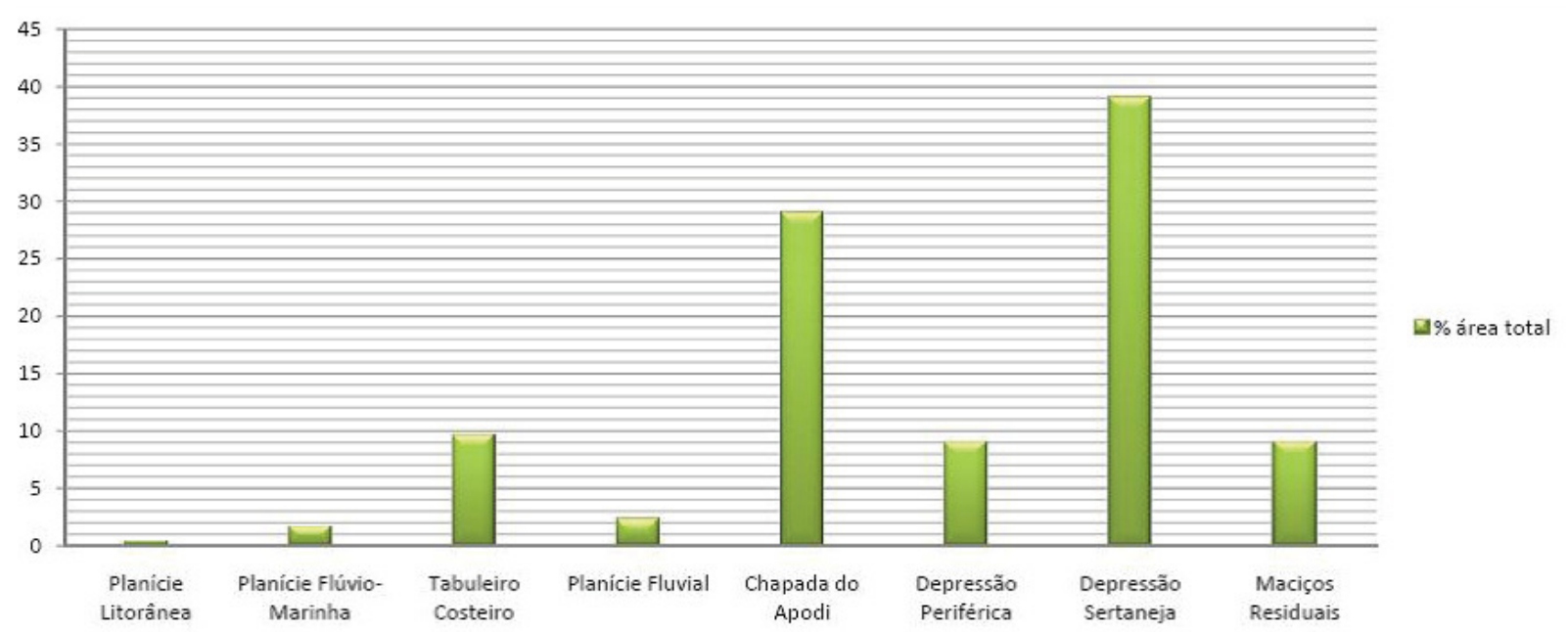

Figura 3 - Percentual de abrangência dos sistemas ambientais na região da BHRAM. Fonte: Adaptado de Carvalho (2011). 
O Quadro 1 apresenta uma contextualização sobre os componentes abióticos (rochas, relevo, clima, recursos hídricos e solos) e bióticos (vegetação) dos sistemas ambientais da região da BHRAM. A situação da estrutura geoambiental nos sistemas deriva da combinação de fatores e processos naturais ocorridos ao longo do tempo geológico, especialmente no Mesozóico e Cenozóico, sendo a organização ambiental derivada de duas principais morfoestruturas: a Bacia Sedimentar Potiguar com influência no setor centro-norte; e o embasamento cristalino com influência no centro-sul da área em questão.

Quadro 1 - Contexto geoambiental da região da BHRAM.

\begin{tabular}{|c|c|c|c|}
\hline $\begin{array}{l}\text { SISTEMAS } \\
\text { AMBIENTAIS }\end{array}$ & $\begin{array}{l}\text { GEOLOGIA/ } \\
\text { GEOMORFOLOGIA }\end{array}$ & $\begin{array}{l}\text { CLIMA/ } \\
\text { RECURSOS HÍDRICOS }\end{array}$ & $\begin{array}{l}\text { SOLOS/ } \\
\text { VEGETAÇÃO }\end{array}$ \\
\hline $\begin{array}{l}\text { PLANÍCIE } \\
\text { LITORÂNEA }\end{array}$ & $\begin{array}{l}\text { Depósitos arenosos inconsolidados } \\
\text { de idade Quaternária. Amplas } \\
\text { faixas de praia, terraços marinhos, } \\
\text { morfologias dunares de gerações } \\
\text { variadas. }\end{array}$ & $\begin{array}{l}\text { Pluviometria variando entre } 600 \\
\text { e } 800 \mathrm{~mm} \text {. Ocorre a infiltração } \\
\text { quase que completa da água, } \\
\text { alimentando o aqüífero dunar, por } \\
\text { vezes aflorando na forma de lagoas } \\
\text { interdunares. }\end{array}$ & $\begin{array}{l}\text { Neossolos Quartzarênicos } \\
\text { e quartzarênicos marinhos. } \\
\text { Vegetação do complexo } \\
\text { litorâneo, predominando a } \\
\text { vegetação pioneira psamófila } \\
\text { e associações de espécies da } \\
\text { caatinga. }\end{array}$ \\
\hline $\begin{array}{l}\text { PLANÍCIE } \\
\text { FLÚVIO- } \\
\text { MARINHA }\end{array}$ & $\begin{array}{l}\text { Depósitos recentes com } \\
\text { predominância de material argiloso, } \\
\text { silte, areia fina e detritos orgânicos. } \\
\text { Ampla planície de acumulação de } \\
\text { sedimentos flúvio-marinhos. }\end{array}$ & $\begin{array}{l}\text { Pluviometria variando entre } 600 \\
\text { e } 800 \text { mm. Ambiente submetido } \\
\text { a hidrodinâmica do rio Apodi- } \\
\text { Mossoró e fluxo marinho. Solos } \\
\text { encharcados e salinos. }\end{array}$ & $\begin{array}{l}\text { Gleissolos. Predomínio de } \\
\text { vegetação de mangue. }\end{array}$ \\
\hline $\begin{array}{l}\text { TABULEIRO } \\
\text { COSTEIRO }\end{array}$ & $\begin{array}{l}\text { Sedimentos terciários diversos } \\
\text { da Formação Barreiras. Relevos } \\
\text { baixos (máximo de } 40 \mathrm{~m} \text { ) e planos a } \\
\text { suavemente ondulados. }\end{array}$ & $\begin{array}{l}\text { Pluviometria variando entre } 600 \\
\text { e } 800 \mathrm{~mm} \text {. Drenagem superficial } \\
\text { mais adensada, presença de lagoas } \\
\text { naturais e recarga do aquífero } \\
\text { barreiras. }\end{array}$ & $\begin{array}{l}\text { Neossolo Quartzarênico e } \\
\text { Latossolos. Vegetação associada } \\
\text { a espécies da caatinga. }\end{array}$ \\
\hline $\begin{array}{l}\text { PLANÍCIE } \\
\text { FLUVIAL }\end{array}$ & $\begin{array}{l}\text { Depósitos constituídos por materiais } \\
\text { de diversos calibres. }\end{array}$ & $\begin{array}{l}\text { Pluviometria variada devido } \\
\text { ao caráter alongado da área. } \\
\text { Superfície sujeita a inundações } \\
\text { periódicas com boa potencialidade } \\
\text { de águas subterrâneas. }\end{array}$ & $\begin{array}{l}\text { Neossolos Flúvicos revestidos } \\
\text { por mata de galeria. Destaque } \\
\text { para as florestas de carnaúba, } \\
\text { que já se encontram bastante } \\
\text { degradadas. }\end{array}$ \\
\hline $\begin{array}{l}\text { CHAPADA DO } \\
\text { APODI }\end{array}$ & $\begin{array}{l}\text { Sedimentos Mesozóicos da } \\
\text { Formação Jandaíra, calcarenitos } \\
\text { e calcilutitos bioclásticos. Relevo } \\
\text { plano, com suave inclinação na } \\
\text { direção do litoral }\left(1^{\circ} \text { a } 3^{\circ}\right) \text {. }\end{array}$ & $\begin{array}{l}\text { Pluviometria variando entre } 600 \\
\text { e } 800 \mathrm{~mm} \text {. Drenagem superficial } \\
\text { escassa. Aquífero com boa } \\
\text { capacidade, em profundidades } \\
\text { variadas, de } 100 \text { a } 1500 \mathrm{~m} \text {. }\end{array}$ & $\begin{array}{l}\text { Cambissolos e Chernossolos. } \\
\text { Vegetação de caatinga, } \\
\text { caducifólia. }\end{array}$ \\
\hline $\begin{array}{l}\text { DEPRESSÃO } \\
\text { PERIFÉRICA }\end{array}$ & $\begin{array}{l}\text { Arenito de origem continental e } \\
\text { idade Mesozóica da Formação Açu. } \\
\text { Faixa estreita de terra, alongada de } \\
\text { leste para oeste. Relevo ondulado. }\end{array}$ & $\begin{array}{l}\text { Pluviometria variando entre } \\
600 \text { e } 800 \mathrm{~mm} . \text { Recursos } \\
\text { hídricos superficiais adensados, } \\
\text { com direções variadas. Relevo } \\
\text { medianamente dissecado. }\end{array}$ & $\begin{array}{l}\text { Argissolos, Latossolos e } \\
\text { Planossolos. Vegetação } \\
\text { caducifólia de caatinga. }\end{array}$ \\
\hline $\begin{array}{l}\text { DEPRESSÃO } \\
\text { SERTANEJA }\end{array}$ & $\begin{array}{l}\text { Rochas cristalinas pré-cambrianas, } \\
\text { como o granito, migmatitos e } \\
\text { gnaisse. Relevo composto por } \\
\text { superfícies de pediplanação e } \\
\text { distribuição esparsa de inselbergs. }\end{array}$ & $\begin{array}{l}\text { Pluviometria variando entre } 700 \\
\text { e } 800 \mathrm{~mm} \text {. Recursos hídricos } \\
\text { superficiais adensados, com } \\
\text { padrão de drenagem dentrítico. } \\
\text { Relevo medianamente dissecado } \\
\text { nos pediplanos e com fortes } \\
\text { inclinações em inselbergs } \\
\text { distribuídos na área. }\end{array}$ & $\begin{array}{l}\text { Argissolos, Neossolos } \\
\text { Regolíticos e Litólicos, } \\
\text { Luvissolos. Vegetação } \\
\text { caducifólia de caatinga. }\end{array}$ \\
\hline $\begin{array}{l}\text { MACIÇOS } \\
\text { RESIDUAIS }\end{array}$ & $\begin{array}{l}\text { Rochas cristalinas com } \\
\text { características de maior resistência } \\
\text { aos processos erosivos. Apresentam } \\
\text { declividades diversificadas, variando } \\
\text { entre } 10^{\circ} \text { e } 45^{\circ} \text { de inclinação das } \\
\text { vertentes. }\end{array}$ & $\begin{array}{l}\text { Pluviometria variando entre } 800 \\
\text { e } 1200 \text { mm. Recursos hídricos } \\
\text { superficiais submetidos a fortes } \\
\text { inclinações. Presença de nascentes } \\
\text { e cachoeiras, acumulações } \\
\text { superficiais e subterrâneas mais } \\
\text { pronunciadas nas áreas de platô. }\end{array}$ & $\begin{array}{l}\text { Argissolos, Neossolos Litólicos. } \\
\text { Vegetação subcaducifólia, } \\
\text { arbustiva e arbórea. Associação } \\
\text { de espécies da caatinga. }\end{array}$ \\
\hline
\end{tabular}

Fontes: EMPARN [200-?a]; EMPARN [200-?b]; Nunes (2006). Elaborado por Rodrigo G. de Carvalho. 
Carvalho (2011) estabeleceu o enquadramento dos sistemas ambientais baseado na ecodinâmica (TRICART, 1977). A partir da avaliação sobre a estrutura e funcionamento, os sistemas ambientais foram classificados (Quadro 2) em meios estáveis, de transição ou fortemente instáveis.

Quadro 2 - Características ecodinâmicas dos sistemas ambientais da BHRAM.

\begin{tabular}{|c|c|}
\hline SISTEMAS AMBIENTAIS & ECODINÂMICA \\
\hline PLANÍCIE LITORÂNEA & $\begin{array}{l}\text { Ambientes fortemente instáveis. A dinâmica ambiental é comandada por processos marinhos e } \\
\text { eólicos. Os sedimentos inconsolidados são constantemente mobilizados dificultando a edafização. }\end{array}$ \\
\hline $\begin{array}{l}\text { PLANÍCIE FLÚVIO- } \\
\text { MARINHA }\end{array}$ & $\begin{array}{l}\text { Ambientes fortemente instáveis. Os solos estão submetidos a intenso processo de transporte } \\
\text { condicionado pelos fluxos fluviais e marinhos, ocorrendo períodos de sedimentação/erosão. }\end{array}$ \\
\hline TABULEIRO COSTEIRO & $\begin{array}{l}\text { Ambientes estáveis. O relevo plano, consorciado com a boa permeabilidade do terreno possibilitou } \\
\text { a evolução pedogenética e a fixação da vegetação de porte arbustivo com moderada capacidade } \\
\text { protetora dos solos. }\end{array}$ \\
\hline PLANÍCIE FLUVIAL & $\begin{array}{l}\text { Ambientes fortemente instáveis. Os solos estão sujeitos continuamente a processos de deposição / } \\
\text { erosão em função das constantes inundações laterais. }\end{array}$ \\
\hline CHAPADA DO APODI & $\begin{array}{l}\text { Ambientes estáveis. Apesar da pouca capacidade protetora da vegetação, as condições do relevo e } \\
\text { a permo-porosidade não favorecem a erosão linear, permitindo a evolução pedogenética. }\end{array}$ \\
\hline DEPRESSÃO PERIFÉRICA & $\begin{array}{l}\text { Ambientes de transição. O relevo levemente movimentado impõe a necessidade da cobertura } \\
\text { vegetal para a proteção do solo à erosão. A pedogênese atua, mas o desmatamento pode acentuar } \\
\text { os processos de transporte. }\end{array}$ \\
\hline DEPRESSÃO SERTANEJA & $\begin{array}{l}\text { Ambientes de transição. O relevo levemente movimentado e a densidade da drenagem impõem } \\
\text { a necessidade da cobertura vegetal para a proteção do solo à erosão. A pedogênese atua, mas o } \\
\text { desmatamento pode acentuar os processos de transporte. }\end{array}$ \\
\hline MACIÇOS RESIDUAIS & $\begin{array}{l}\text { Ambientes de transição tendendo a fortemente instáveis a partir do desmatamento. Apesar da } \\
\text { grande capacidade protetora da vegetação e evolução pedogenética, o relevo pode facilmente } \\
\text { acionar processos morfogenéticos concentrados, como escorregamentos, deslizamentos ou } \\
\text { solifluxão. A manutenção da vegetação é fator crucial para a estabilidade ecológica. }\end{array}$ \\
\hline
\end{tabular}

Fonte: Carvalho, 2011.

\section{SISTEMAS AMBIENTAIS E O DESMATAMENTO NA REGIÃO DA BHRAM}

Para a análise do desmatamento na região da BHRAM descartou-se o sistema ambiental planície litorânea, visto que essa unidade de paisagem possui pouca representatividade dimensional, assim como, pouco revestimento vegetal.

Os sete sistemas ambientais restantes possuíam, até o ano de 2008 , no total, $5.790 \mathrm{~km} 2$ de áreas desmatadas, o que representa $37,8 \%$ da região da BHRAM. Esse percentual é sustentado pelos dois maiores sistemas ambientais em questão (Figura 4), quais sejam: a depressão sertaneja e a chapada do Apodi, respectivamente com $28 \%$ e $37 \%$ de áreas desmatadas.

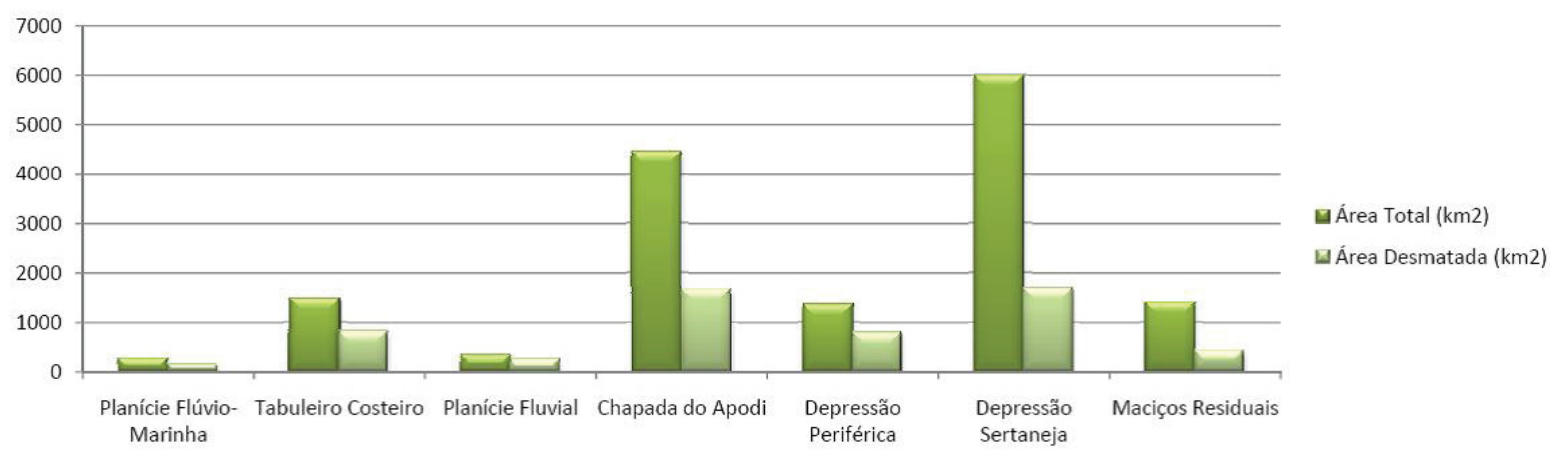

Figura 4 - Valores absolutos aproximados da área territorial dos sistemas ambientais e das áreas desmatadas na região da BHRAM.

Fonte: Adaptado de Carvalho (2011).

Já a planície flúvio-marinha, o tabuleiro costeiro, a planície fluvial e a depressão periférica apresentam, respectivamente, 58\%, 55\%, 74\% e 58\% de áreas desmatadas (Figura 5). Estudos 
realizados em bacias e microbacias hidrográficas, em diferentes biomas brasileiros, constatam que o excesso de desmatamento é um dos principais problemas ambientais, difusor de efeitos como a erosão, o assoreamento e a desertificação (NASCIMENTO, 2009; CARPI JUNIOR; MALAQUIAS JUNIOR, 2008; CAVALCANTE; ARRUDA, 2008; SOBRINHO; ROSS, 2007; SOUSA; LIMA, 2007). Esse fato é agravado quando o desmatamento incide sobre sistemas ambientais fortemente instáveis, como é o caso da planície flúvio-marinha e da planície fluvial.

Os maciços residuais apresentam um percentual de 30\% de áreas desmatadas. Comparativamente aos outros sistemas ambientais, os maciços residuais se tornam importantes por apresentarem terrenos fortemente dissecados, com declividades variando entre 10o e 45o. Essa característica impõe sérias restrições ao uso da terra, especialmente quando esse uso resultar em desmatamentos de áreas com declividades acentuadas.

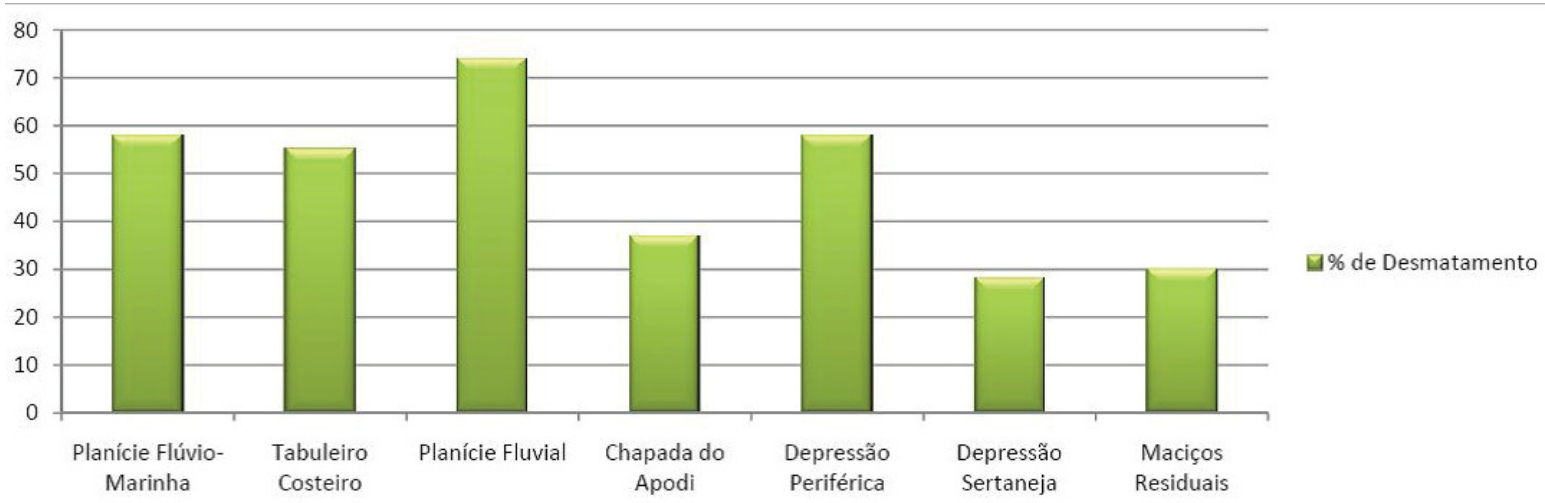

Figura 5 - Percentual de desmatamento nos sistemas ambientais da região da BHRAM. Fonte: Carvalho, 2011.

Considerando os diversos impactos e os desequilíbrios gerados em bacias hidrográficas pelo desmatamento, torna-se fundamental para a sustentabilidade dos sistemas ambientais em questão o monitoramento do desmatamento, a proposição de formas adequadas de manejo da vegetação, do solo e da água, a recuperação de áreas degradadas, a manutenção de áreas de preservação permanente e a criação de unidades de conservação.

Silva e Ferreira Júnior (2010) apontam que o monitoramento da vegetação, associada à análise de outros fatores como, por exemplo, de ordem política, econômica ou social são indispensáveis a efetiva gestão territorial e ambiental. Trigueiro, Oliveira e Bezerra (2009), estudando um município no semiárido brasileiro, enfatizaram que atividades como a agropecuária e o extrativismo vegetal, sem o devido manejo, provocam o desgaste e o empobrecimento do solo, sendo fundamental a adoção de técnicas compatíveis com a conservação da qualidade dos solos.

Com base nos dados estruturais e funcionais levantados sobre os sistemas ambientais da BHRAM, associados à situação do desmatamento até o ano de 2008 segundo dados do projeto "Monitoramento do Desmatamento nos Biomas Brasileiros por Satélite", indicam-se no Quadro 3 o diagnóstico dos sistemas ambientais face ao processo de desmatamento e as medidas de gestão que podem contribuir para melhorar a sustentabilidade a médio e longo prazo nos sistemas ambientais em questão. 


\section{DIAGNÓSTICO AMBIENTAL E MEDIDAS \\ MAPAS COM A ESPACIALIZAÇÃO DAS \\ DE GESTÃO NOS SISTEMAS AMBIENTAIS \\ ÁREAS DESMATADAS ATÉ O ANO DE 2008}

Planície Flúvio-Marinha - Diagnóstico

Ambiental: Sistema ambiental fortemente

instável, comportando complexa cadeia biológica a partir da interface oceano/continente. O percentual de $58 \%$ de desmatamento pode estar

superestimado em razão da atividade salineira.

Contudo, o desmatamento compromete a

sustentabilidade do manguezal e da fauna

estuarina. Medidas de Gestão: Como medidas de manejo recomendam-se a recuperação de áreas de mangue, a proteção dos remanescentes por meio da instituição de monitoramento e fiscalização permanentes e da criação de áreas protegidas e a instituição de atividades de educação ambiental e turismo ecológico para valorizar a conservação da vegetação.

\section{Tabuleiro Costeiro - Diagnóstico Ambiental:}

Sistema ambiental estável, com dinâmica evolutiva branda, evolução dos solos e relevo plano a suavemente ondulado. Pouco potencial para o desenvolvimento de erosões importantes. O percentual de $55 \%$ de desmatamento está vinculado a atividades agropecuárias, com destaque para a fruticultura irrigada. Medidas de

Gestão: O desmatamento ocorre de forma espalhada sendo importante manter áreas com remanescente de vegetação e estabelecer corredores para o fluxo gênico. Deve-se priorizar a fiscalização das reservas legais e áreas de preservação permanente.

\section{Planície Fluvial - Diagnóstico Ambiental:}

Sistema ambiental fortemente instável em razão da dinâmica fluvial. Intenso processo de erosão e, no baixo curso, com o assoreamento, as inundações podem ser potencializadas e promover catástrofes espasmódicas. O percentual de $74 \%$ de desmatamento reflete o nível de comprometimento das matas de galeria, em parte, constituídas como áreas de preservação permanente. Medidas de Gestão: Sugere-se o estabelecimento de programas de educação ambiental e acompanhamento das atividades desenvolvidas pelos empreendimentos rurais e a recuperação de áreas fortemente degradadas. Necessidade de pesquisa sobre o balanço sedimentológico dos rios Apodi-Mossoró e rio do Carmo.
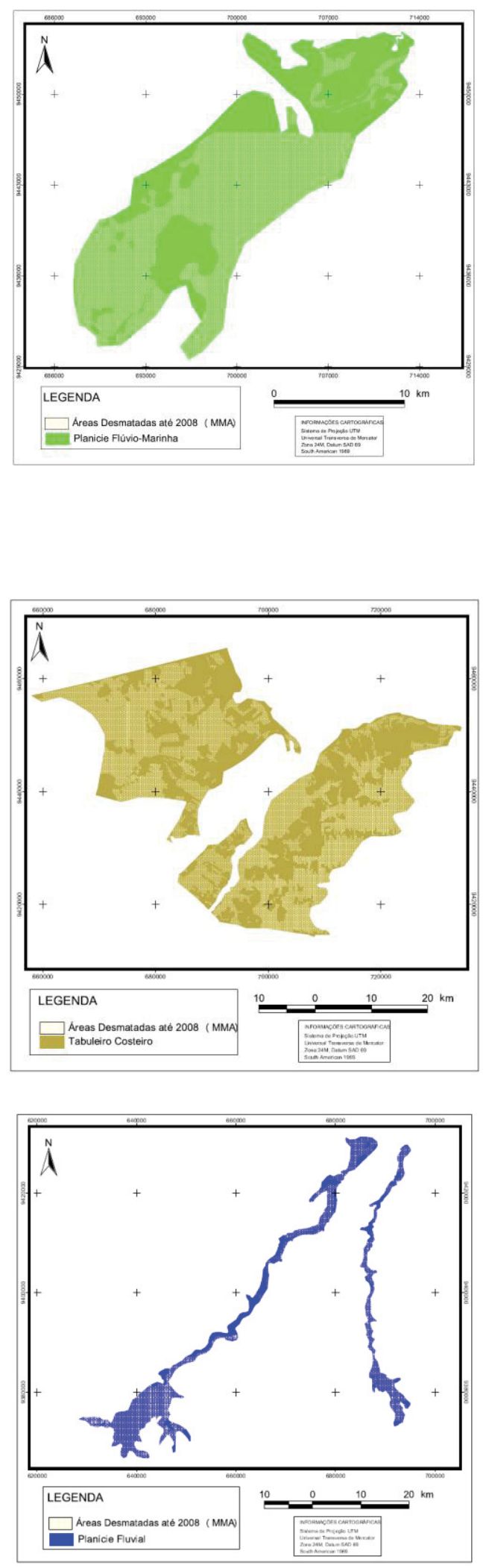

Quadro 3 - Situação dos sistemas ambientais físicos na BHRAM frente ao processo de desmatamento e medidas de gestão. 


\section{Chapada do Apodi - Diagnóstico Ambiental:}

Sistema ambiental estável, com solos incipientes, drenagem superficial escassa, relevo plano a suavemente ondulado com pouco potencial para erosão. O percentual de $37 \%$ de desmatamento está vinculado, especialmente, a atividades agrícolas, ao aumento de assentamentos de reforma agrária e da exploração do petróleo (MELO; GRIGIO; DIODATO, 2011). Medidas de Gestão: Devem-se instituir unidades de conservação visando proteger remanescentes de mata e manter corredores ecológicos. Fiscalização permanente nas reservas legais.

\section{Depressão Periférica - Diagnóstico Ambiental:}

Sistema ambiental de transição. O relevo

levemente movimentado impõe a necessidade da cobertura vegetal para a proteção do solo à erosão. O desmatamento pode acentuar os processos de transporte. O percentual de $58 \%$ de desmatamento vincula-se a forte pressão agropecuária exercida mediante a alta densidade da drenagem superficial. Intensos riscos de processos erosivos lineares e degradação das terras. Medidas de Gestão: A sustentabilidade dessa unidade de paisagem requer uma ação forte do poder público com o intuito de fiscalizar e promover formas de manejo da vegetação de caatinga, do solo e da água.

\section{Depressão Sertaneja - Diagnóstico Ambiental:}

Sistema ambiental de transição. O relevo levemente movimentado e a densidade da drenagem impõem a necessidade da cobertura vegetal para a proteção do solo à erosão. Situação muito parecida com a depressão periférica, mas com a diferença da ocorrência de afloramentos rochosos e existência de solos rasos e pedregosos, colocando essa unidade de paisagem como uma área potencial para o desenvolvimento de processos de desertificação. Medidas de Gestão: O desmatamento de $28 \%$ da área ocorre, na maior parte, concentrado em grandes poligonais. Em razão disso, deve se monitorar a degradação das terras e sua evolução para a desertificação.
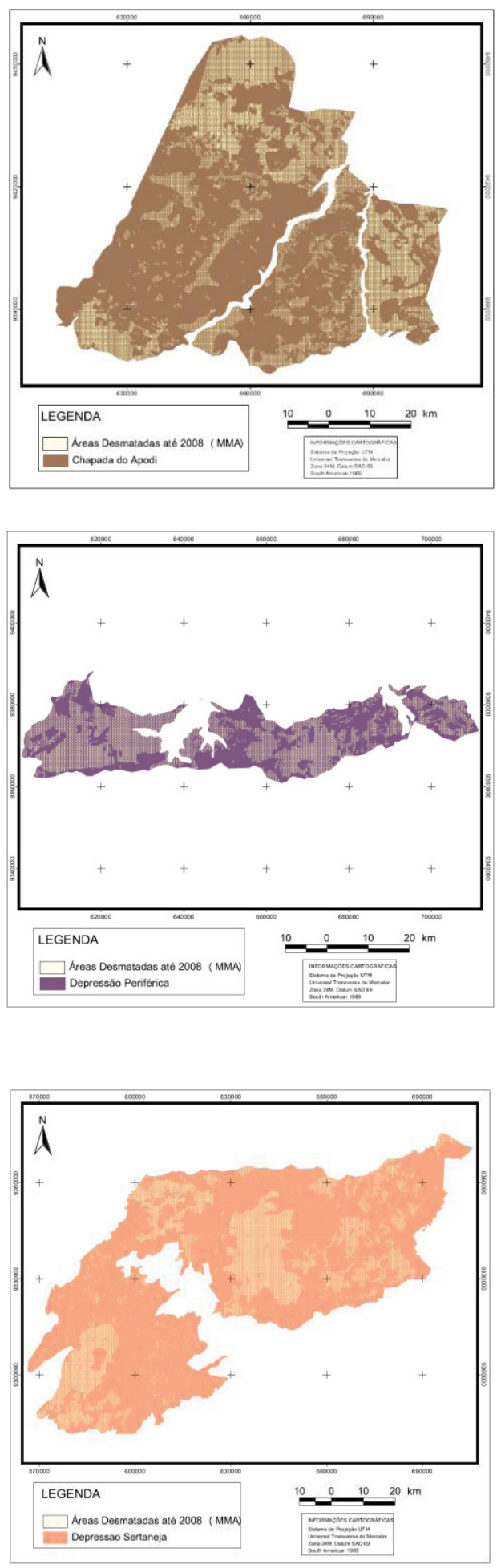

Quadro 3 - Situação dos sistemas ambientais físicos na BHRAM frente ao processo de desmatamento e medidas de gestão (cont.). 


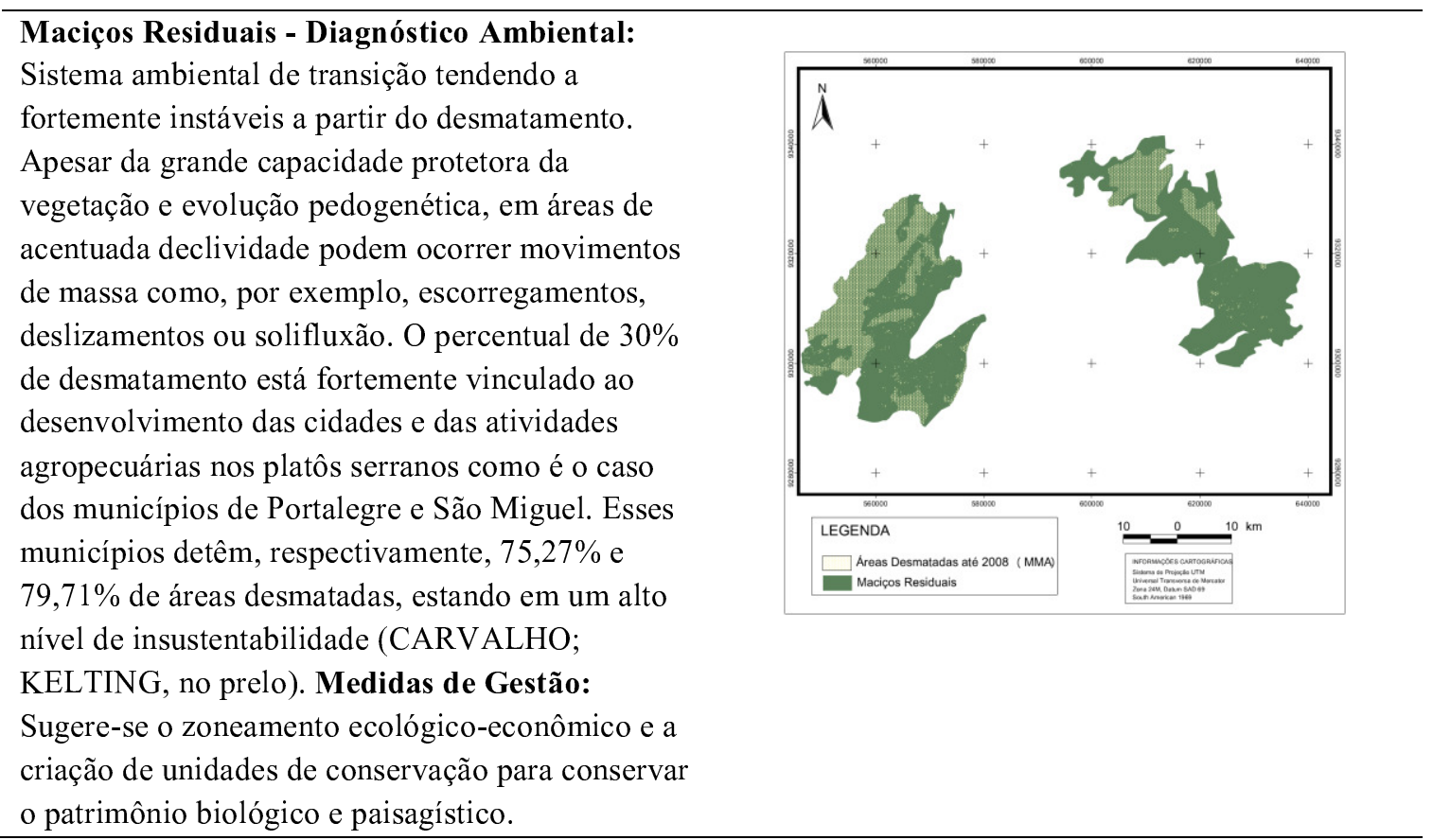

Quadro 3 - Situação dos sistemas ambientais físicos na BHRAM frente ao processo de desmatamento e medidas de gestão (cont.).

\section{CONSIDERAÇÕES FINAIS}

O estudo apresentado permite apontar as seguintes conclusões:

i. a região da BHRAM comporta sistemas ambientais diversos, desenvolvidos a partir de duas morfoestruturas principais: a Bacia Potiguar e o embasamento cristalino;

ii. o estudo da morfodinâmica aponta para a existência de sistemas ambientais fortemente instáveis (planície flúvio-marinha; planície fluvial), de transição (depressão periférica; depressão sertaneja e maciços residuais) e estáveis (tabuleiro costeiro e chapada do Apodi);

iii. o desmatamento total da região da BHRAM chega a 37,8\%, estando dentro de um limite tolerável para o Bioma Caatinga, porém, existem grandes diferenças entre os percentuais de desmatamento nos sistemas ambientais;

iv. sistemas ambientais fortemente instáveis apresentam elevados percentuais de desmatamento como a planície flúvio-marinha $(58 \%)$ e a planície fluvial $(74 \%)$.

v. cada sistema ambiental requer medidas de gestão específicas em razão da estrutura e funcionamento da paisagem, das atividades socioeconômicas e do desmatamento resultante.

\section{REFERÊNCIA BIBLIOGRÁFICA}

BERTRAND, G. Paisagem e Geografia Física global: esboço metodológico. Caderno de Ciências da Terra, v. 13, p. 1-21. São Paulo, 1969.

BERTRAND, G.; BERTRAND C. Uma geografia transversal e de travessias: o meio ambiente através dos territórios e das temporalidades. In: BERTRAND, G. (Org.) ; BERTRAND, C. (Org.) ; PASSOS, M. M. (Org.) . Uma geografia transversal e de travessias (O meio ambiente através dos territórios e das temporalidades). 1a.. ed. Maringá: Editora Massoni, 2007.

CARPI JUNIOR, S.; MALAQUIAS JUNIOR, J. R. Dinâmica ambiental em microbacias hidrográficas de Monte Mor - SP. OLAM - Ciência e Tecnologia. Rio Claro - SP. v. 8, no 3, p. 85 -110, jul/dez, 2008. 
CARVALHO, R. G.de. Análise de sistemas ambientais aplicada ao planejamento: estudo em macro e mesoescala na região da bacia hidrográfica do rio Apodi-Mossoró, RN/Brasil. Tese (Doutorado em Geografia), Curso de Pós-Graduação em Geografia, Universidade Federal do Ceará, Fortaleza, 2011.

CARVALHO, R. G. DE.; KELTING, F. M. S. Construção de um índice de estado do meio ambiente para os municípios da região da bacia hidrográfica do rio Apodi-Mossoró, RN. Boletim de Geografia, no prelo.

CAVALCANTE, M. B.; ARRUDA, L. V. O planejamento dos recursos hídricos na caatinga: um olhar sobre as condições ambientais do rio Calabouço - PB/RN. Revista Caminhos de Geografia. Uberlândia - MG. v. 9 , n. 28 , p. $221-231$, dez., 2008.

CHRISTOFOLETTI, A. Modelagem em Sistemas Ambientais. São Paulo: Edgard Blücher, 1999.

CUNHA, S. B.; GUERRA, A. J. T. Degradação ambiental. In: Guerra, A. J. T.; Cunha, S. B. Geomorfologia e meio ambiente. $3^{\circ}$ ed., Rio de Janeiro: Bertrand Brasil, 2000.

EMPARN - Empresa de Pesquisa Agropecuária do Rio Grande do Norte. Mapa de Temperatura Anual. [200-?a]. Acesso em 16/08/2010. Disponível em http://www.emparn.rn.gov.br/contentproducao/aplicacao/ emparn/arquivos/meteorologia /climatologia/temperatura.htm

EMPARN - Empresa de Pesquisa Agropecuária do Rio Grande do Norte (EMPARN). Mapa de Precipitação Anual. [200-?b]. Acesso em 16/08/2010. Disponível em http://www.emparn.rn.gov.br/contentproducao/ aplicacao/emparn/arquivos/meteorologia/climatologia/PrecClimatologica/anochuva.htm

MMA - Ministério do Meio Ambiente. Monitoramento do desmatamento dos biomas brasileiros por satélite / Monitoramento do bioma caatinga. (Relatório Técnico). Centro de Sensoriamento Remoto, Brasília, 2010. Acesso em 25 de março de 2010. Disponível em: http://www.mma.gov.br/sitio/index. php?ido $=$ conteudo.monta\&idEstrutura $=146$

MELO, E. R. S.; GRIGIO, A. M.; DIODATO, M. A. Mapeamento e análise da evolução do uso e ocupação do solo no município de Mossoró - RN. In: Carvalho, R. G. et al. Gestão Ambiental: estudos aplicados à região da bacia do rio Apodi-Mossoró. Mossoró, RN: Edições UERN, 2011.

NASCIMENTO, F. R. Identificação de áreas susceptíveis à desertificação em bacia intermitente sazonal no simi-árido brasileiro. Boletim Goiano de Geografia. Goiania - GO. v. 29, no 2, p. 71 - 82, jul / dez, 2009. NUNES, E. Geografia Física do Rio Grande do Norte. Natal: Imagem Gráfica, 2006.

RODRIGUEZ, J. M. M.; SILVA, E. V. DA.; CAVALCANTI, A. P. B. Geoecologia das paisagens: uma visão geossistêmica da análise ambiental. Fortaleza: Edições UFC, 2004.

SÁNCHEZ, L. E. Avaliação de impacto ambiental: conceitos e métodos. São Paulo: Oficina de Textos, 2006. SILVA, E. B.; FERREIRA JUNIOR, L. G. Taxas de desmatamento e produção agropecuária em Goiás 2003 a 2007. Revista Mercator. Fortaleza - CE. ano 9, n. 18, 2010.

SOARES, F. M. Unidades de relevo como proposta de classificação das paisagens da bacia do rio Curu - Estado do Ceará. Tese de Doutorado, Departamento de Geografia - USP, 2001.

SOBRINHO, J. F.; ROSS, J. L. S. O processo de erosão em ambiente de superfície sertaneja - Varjota (CE). Revista GEOUSP - Espaço e Tempo. São Paulo - SP. n 21, 2007.

SOUSA, A. S.; LIMA, C. V. Capacidade de uso das terras como suporte ao planejamento ambiental na bacia hidrográfica do ribeirão Santo Antônio - Iporá-GO. Boletim Goiano de Geografia. Goiania - GO. v. 27, no 3, p. $91-101$, jul / dez, 2007.

SOUSA, M. J. N. de. Compartimentação geoambiental do Ceará. In: Ceará: um novo olhar geográfico. SILVA, J. B. da. et al. 2a ed. Fortaleza: Edições Demócrito Rocha, 2007.

TRICART, J. Ecodinâmica. Rio de Janeiro: IBGE/SUPREN, 1977. 91p.

TRIGUEIRO, E. R. DA C.; OLIVEIRA, V. P. V.; BEZERRA, C. L. F. Indicadores biofísicos e a dinâmica da degradação / desertificação no bioma caatinga: estudo de caso no município de Tauá, Ceará. REDE Revista Eletrônica do PRODEMA. Fortaleza-CE. v. 3, n. 1, p. 62 - 82, jun., 2009.

Trabalho enviado em maio de 2012 Trabalho aceito em junho de 2012 